\title{
Japan seeks to reverse drop in interest in science
}

Tokyo. Faced with a declining interest among young Japanese in pursuing careers in science and engineering, Japan's Ministry of Education, Science and Culture last week set up an advisory committee made up largely of young researchers to produce ideas about ways of reversing this trend.

The tendency for young Japanese to turn their backs on science and engineering has been evident for several years. In 1989, for example, the National Institute of Science and Technology Policy (NISTEP) reported a sudden drop in the number of science and engineering graduates entering manufacturing industry, and a surge in those going into finance (Nature 338, 102; 1989).

At the time, it was not clear whether this was a temporary phenomenon associated with Japan's then booming stock market. More recent studies suggest the change is deep-rooted. For example, the annual white paper (policy document) on science and technology, released by the Science and Technology Agency in December, produces several indicators to show young people's declining interest in science.

In the early $1980 \mathrm{~s}$, more than half $(56$ per cent) of young people in their 20 s expressed interest in news and topics concerning science and technology, larger than the percentage for older age groups. But by November 1991, the proportion of 20-yearolds had fallen to 41 per cent, far less than in older groups.

This trend is reflected in the percentage of applicants to science and engineering faculties at universities, which, according to a ministry of education survey, peaked at more than 25 per cent in 1986 , but has since fallen to less than 20 per cent.

Furthermore, another survey last month by the education ministry of 57 deans of engineering and science faculties at national and private universities shows that by far the majority (44) feel that the best students are no longer choosing to study science and engineering.

In a departure from tradition, the ministry's committee, which will be chaired by Yasuharu Suematsu, emeritus professor of Tokyo Institute of Technology, includes many relatively young members still in their $30 \mathrm{~s}$ and $40 \mathrm{~s}$, and three women.

The committee is expected to make its recommendations in June and is likely to call for dramatic improvements in the research environment in universities, for revisions in curricula, and for more open days for schoolchildren to visit university laboratories. It is also expected to urge universities and industry to form a closer alliance to improve career prospects for scientists and engineers.

\section{Soros pledges more money to back Russian science}

Moscow. George Soros, the Hungarian born financier, has agreed to provide a further $\$ 12.5$ million to the International Science Foundation (ISF), the private organization which he set up two years ago with an initial grant of $\$ 100$ million to provide support for Russian scientists.

Soros' decision, which was announced in Moscow on Monday, follows a promise by the Russian government that it is prepared to contribute a similar sum to the foundation. Earlier, Soros had said that he would only provide additional funding for the ISF if the organization was able to raise matching funds from other sources.

Speaking at a press conference which was also attended by Boris Saltykov, the Russian minister for science and technology policy, and James Watson, the Nobel laureate and current chairman of the ISF, Soros said that he had been impressed by the work of the foundation over its first two years, and in particular the efficiency with which its activities had been organized.

He also emphasized his desire to continue to provide support for other activities of the foundation, including the assistance provided to scientists for the purchase of foreign journals and, most importantly, for the development of electronic communications.

During his visit to Moscow, Soros signed an agreement with the Russian government aimed at developing the use of computer networks in Russia. He expressed a desire to see the new networks enlarged to cover

libraries and other cultural organizations.

In addition to the new financial commitment from both Soros and the Russian government, the foundation has set itself the target of raising $\$ 60$ million from both the United States and other foreign governments. At present, however, there is little indication of how much of this money will be made available.

The results of the earlier round of awards made by the ISF show that about one fifth of the nine thousand applications received were approved, with the size of most of the grants varying from $\$ 10,000$ to $\$ 50,000$.

According to Pavel Arseniev, the head of the ISF programme, a lack of funds meant that the value of the largest grant had to be cut from a promised $\$ 100,000$ to $\$ 69,000$. But he says that the overall success of the programme is reflected in the large number of applicants for awards.

Despite the lack of funds, the ISF staff decided to increase the number of grants to be awarded, reducing the payment schedule from two to one-and-a-half years. As a result, financing will end in the summer of 1995 , rather than in December as originally planned.

Meeting in Moscow on Monday, the executive board of the ISF approved recommendation from its expert committees for the distribution of about $\$ 32$ million in long-term grants. A further $\$ 13$ million is due to be awarded in the second round this autumn.

Carl Levitin

\section{Marie Curie 'should rest in Panthéon'}

Paris. Marie Curie may become the first women to be buried in France's national mausoleum, the Panthéon. The proposal was made on international women's day last week by François Mitterrand, the French president, in response to protests from leading female personalities - including Simone Veil the health minister - that at the end of the twentieth century it was absurd that the official recognition symbolized by the Panthéon was still reserved for men.

In 1903, Curie became the first woman to win the Nobel Prize for Physics, along with her husband Pierre, for the discovery of radioactivity.

In 1911, she became the first woman to win a second Nobel Prize, this time for chemistry. But in the same year the
French Academy of Sciences turned down her application for entry, saying "let in anyone, except women". Her daughter Irene, won the Nobel Prize for chemistry in 1935, with her husband Frédéric.

Technically speaking, Marie Curie

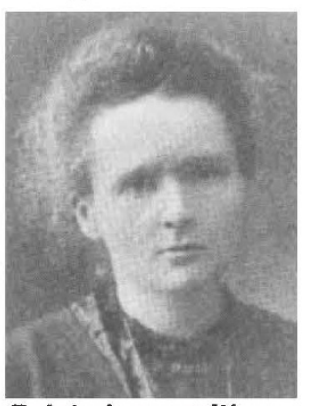

Belated recognition. will be the second woman to be buried with figures such as Voltaire, Rousseau, and Victor Hugo. The remains of Marguerite Berthelot were placed beside those of her husband, the chemist Marcellin, as he had stipulated in his will.

All that now stands in the way of Mitterrand's wish is the consent of Marie-Curie's relatives. If they agree, they are likely to ask that Pierre accompany her; and the Panthéon will have to insert "femmes" into its motto, "aux grands hommes."
Declan Butler 